\title{
Sobre a (im)possibilidade de dar voz aos usuários das políticas públicas: reflexões a partir da prática intersetorial
}

\author{
The (im)possibility of giving voice to users of public policies: \\ reflections from intersectoral practice
}

\section{Sobre la (im)posibilidad de dar voz a los usuarios de las políticas públicas: reflexiones a partir de la práctica intersectorial}

Roberta Carvalho Romagnoli ic

\begin{abstract}
Resumo: Esse artigo coloca em análise as relações da prática intersetorial com as famílias no Núcleo Intersetorial Regional Técnico (NIR-T) de uma das regionais de Belo Horizonte, espaço para a discussão de casos graves de violação social. Esse estudo tem a pesquisa-intervenção como metodologia e as ideias de Deleuze e Guattari e René Lourau como marco teórico. No processo da pesquisa tivemos dificuldades com as entrevistas com as famílias, que não puderam ser escutadas como planejado. Examinamos essa inviabilidade como um analisador, que torna visível a tensão do que é reproduzido pelas instituições, mas também a produção do novo, do que gera conflito. Constatamos a presença de alguns "não ditos" institucionais: a mudança de prefeito, a proteção dos profissionais e das famílias, a passividade, mas também a necessidade de sustentar a diferença das famílias. Concluímos que a avaliação das políticas públicas pelos usuários é essencial para a sustentação da prática intersetorial.
\end{abstract}

Palavras-chave: Família. Intersetorialidade. Intervenção Psicossocial.

Abstract: This paper analyzes the intersectorial practice relations with the families in the Regional Technical Intersectorial Nucleus (NIR-T) Technical Regional Intersectorial Nucleus (NIR-T), in one of the Belo Horizonte's regional, a space for discussion of serious cases of social violation. This study has the intervention research as methodology and the ideas of Deleuze and Guattari and René Lourau as theoretical framework. In the process of the research, we had difficulties to make interviews with the families that could not be listened like planned. We examine this impossibility as an analyzer, which makes visible the tension of the reproduction in the institutions, but also of the production of the new, of which it generates conflict. We noticed the presence of some institutional "not-saids": the change of the city mayor, the protection of professionals and families, passivity, but also the need to support the difference of families. We conclude that the evaluation of public policies by users is essential for the intersectorial practice.

Keywords: Family. Intersectoriality. Psychosocial Intervention.

Resumen: Este artículo pone en análisis las relaciones de la práctica intersectorial con las familias en el Núcleo Intersectorial Regional Técnico (NIR-T) de una de las regionales de Belo Horizonte, espacio para la discusión de casos graves de violación social. Este estudio tiene como metodología la investigación-intervención y como marco teórico las ideas de Deleuze y Guattari y René Lourau. En el proceso de investigación tuvimos dificultades con las entrevistas con las familias, que no pudieron ser escuchadas como planeado. Examinamos esa inviabilidad como un analizador, que hace visible la tensión de lo que es reproducido por las instituciones y también la producción de lo nuevo, de lo que genera conflicto. Constatamos la presencia de algunos "no dichos" institucionales: el cambio de alcalde, la protección de los profesionales y de las familias, la pasividad, pero también la necesidad de sostener la diferencia de las familias. Concluimos que la evaluación de las políticas públicas por los usuarios es esencial para la sustentación de la práctica intersectorial.

Palabras clave: Familia. Intersectorialidad. Intervención Psicosocial.

\footnotetext{
${ }^{1}$ Submetido em: 03 dez. 2018 - Aceito em: 11 fev. 2019 - Publicado em: 15 fev. 2019

${ }^{2}$ Pontifícia Universidade Católica de Minas Gerais (PUC Minas) - E-mail: robertaroma1@ gmail.com
} 


\section{Prática intersetorial e famílias}

Esse texto pretende colocar em análise evidenciar as tensões e forças vividas nos (des)encontros com as famílias cujos casos são problematizados no Núcleo Intersetorial Regional Técnico (NIR-T) de uma regional de Belo Horizonte. O NIR-T é um espaço intersetorial para discussão dos casos graves de violação de direitos assistidos pelas políticas de saúde, saúde mental, assistência social e educação, na busca de agilizar e qualificar a entrega de serviços públicos à população demandante. Esse espaço é formado por profissionais que buscam assegurar a interlocução entre as gerências das políticas setoriais regionais, apoiando a sua função nas intervenções dos casos levados para discussão, sustentando assim as ações coletivas e coordenadas. É necessário destacar que o que é aqui apresentado foi produzido mediante experimentações de uma produção de conhecimento interventiva e implicada, exercitando uma postura nômade, que persegue os coletivos e acredita em sua potência; ciência minoritária que visa conhecer ao mesmo tempo em que intervém.

O que queremos dizer, na verdade, é que os corpos coletivos sempre têm franjas ou minorias que reconstituem equivalentes de máquina de guerra, sob formas por vezes muito inesperadas, em agenciamentos determinados tais como construir pontes, construir catedrais, ou então emitir juízos, ou compor música, instaurar uma ciência, uma técnica [...] (DELEUZE; GUATTARI, 1997, p. 32).

Buscando construir pontes e se associar, a intersetorialidade é uma estratégia necessária para as políticas públicas, uma vez que articula sujeitos de diferentes setores, com saberes e poderes distintos com o intuito de combater problemas complexos. Mais do que um conceito, é uma prática social que vem sendo construída a partir da insatisfação com as respostas de cada setor como nos lembram Warschauer e Carvalho (2014). Monnerat e Souza (2011) também destacam a imprescindibilidade de um enfrentamento intersetorial, através da construção de uma rede de proteção social, principalmente em um país com grandes limites estruturais e desigualdades sociais. As intervenções convocadas neste domínio ultrapassam a competência de um só setor de governo ou área de política pública dada sua complexidade.

Embora seja reconhecida como essencial, a prática intersetorial apresenta uma série de dificuldades e desafios em sua institucionalização. Nesse contexto, o NIR-T tenta sanar essa lacuna. Instituído na regional estudada desde 2013, organiza-se através de uma equipe permanente composta por três profissionais que representam a política da assistência social, da saúde e da educação e também de equipes volantes. São equipes, compostas por profissionais atuantes nos equipamentos dessas mesmas políticas, que solicitam a discussão de um caso específico em atendimento e muitas vezes demandam a presença de profissionais de outros equipamentos, quando necessários para a construção de encaminhamentos. Neste contexto, a equipe fixa do NIR-T organiza o seu funcionamento mensal e quando uma equipe de profissionais tem dificuldade com determinado caso, solicita ir à reunião e são chamados os responsáveis de todos os equipamentos que trabalham com a família em questão.

As estratégias de promoção da saúde e social bem como o enfrentamento da exclusão social não são alvo somente das políticas que compõe esse núcleo, mas do conjunto das 
políticas públicas, desvelando a necessidade de intervenção conjunta. Políticas que têm como sustentáculo a família em suas ações cotidianas, lócus privilegiado e insubstituível de proteção e socialização primárias. No entanto, essa relação das equipes com as famílias se dá de forma conflituosa e desafiadora, em realidades complexas, multideterminadas e bastante precarizadas, principalmente em uma sociedade altamente desigual e heterogênea como a nossa e com grupos familiares singulares que não se assemelham ao modelo dominante de família nuclear. Atravessadas pelo vetor sobrevivência, esses grupos possuem outra lógica de organização, como alternativas para lidar com o desamparo e a exclusão social, muitas vezes desconhecidas pelos profissionais.

Todas as discussões dos casos do NIR-T giram em torno dos problemas apresentados pelas famílias, em geral muito vulneráveis e fragilizadas. Negligências de várias ordens, ameaças de morte, uso constante de crack, álcool e outras drogas, recusa de tratamento apropriado para transtornos mentais, agressões e violências de todos os tipos, falta de suporte familiar ou comunitário para membros doentes e com deficiência, não atendimento das condicionalidades do Programa Bolsa Família, infrequência na escola por problemas relacionados ao tráfico de drogas, dentre outros, aparecem no cotidiano desses grupos deixando as equipes impotentes frente a estes problemas que sempre vêm associados entre si. Nesse cenário, corre-se ainda o risco da naturalização da miséria sem problematizar a produção perversa da exclusão social em nosso país, como apontam Oliveira e Heckert (2013). Esquecendo-se das condições outras que também produzem o cotidiano dessas famílias, os profissionais podem exercer uma gerência dessas subjetividades, normatizandoas, perseguindo-as na correção de seus desvios. Preocupadas com a disciplinarização e regulamentação de modos de existência da família, Santos, Heckert e Carvalho (2017) denunciam estratégicas biopolíticas na qual o poder investe no governo da população e gestão da vida, através desse grupo.

Nesse contexto, dispusemo-nos a escutar essas famílias a respeito das intervenções da qual eram objeto, sobre o que achavam das ações intersetoriais e como viam as equipes, apostando na potência da vida, para além da vulnerabilidade designada pelas políticas que atendiam esses grupos. Parte das tensões decorrentes dessa proposta são apresentadas nesse texto.

\section{O processo de conhecer/intervir}

Considerando as forças que compõem a realidade, bem como as demandas sociais de contribuição real da academia, este estudo se insere na linha de pesquisa-intervenção. Ao discutir os modos de fazer pesquisa no campo social, Amador, Lazzarotto e Santos (2015, p. 230) apontam que essa modalidade de pesquisa "[...] se afirma como certa política de abordagem do próprio social, isto é, como certo modo de concebê-lo e de problematizá-lo". Essa concepção se sustenta na ideia de que o social não é dado a priori, mas sim construído e produzido em nossas práticas, inclusive científicas, se exercendo de forma processual. Nesse sentido, desmancha as dicotomias sujeito-objeto, teoria-prática, unindo pesquisador e população pesquisada em uma produção coletiva de conhecimento, pois “[...] sempre se 
realiza por um mergulho na experiência que agencia sujeito e objeto" (PASSOS; BARROS, 2015 , p. 17). Imersão esta que põe no mesmo plano o conhecer e o transformar, criando dispositivos para alargar a relação com a realidade, com as pessoas que estudamos e com as práticas sociais, na qual não há regras prontas, mas sim uma coprodução que exige a habitação do campo de pesquisa e a análise constante da implicação do pesquisador. Entendemos, desse modo, que conhecer é produzir realidades, interferindo e movendo-as ao mesmo tempo em que nós, pesquisadores, também nos desestabilizamos, criamos zonas de indagação e outros modos de nos subjetivar. Certamente, para ir além do que é dado, perseguir a diferença é um devir necessário, rastro que desemboca nas linhas de virtualidades, no aglomerado de forças que acompanha situações. A diferença, como processo da multiplicidade, revela-se como um plano para além da normalização e da padronização da vida, plano de consistência, que agrupa heterogeneidades e possibilidades.

Na pesquisa-intervenção, a realidade se processa através de formas e forças, que coexistem no cotidiano do processo de produção de conhecimento. As formas têm um funcionamento binário e excludente, operando através de normas e modelos homogeneizantes que organizam e classificam o cotidiano da pesquisa, correspondem ao que está instituído e tende a se repetir. As forças buscam agenciamentos, velocidades e heterogêneos, funcionando de uma maneira conectiva através de desestabilizações produzidas pelas relações, pelas práticas, pelos encontros que fazem com que nós todos envolvidos na pesquisa ousemos experimentar novos modos de atuação. As experiências com esse "fora" (fora de nós, da universidade, dos setores, da nossa formação, do usual...) que a desestabilização nos traz, nos perturbam, nos causam estranhamentos e mal-estar, nos colocam em crise. Essas experiências nos lançam em estados que nada têm a ver com as formas dominantes e instituídas nas quais reconhecemos a nós mesmos, já que são seu limite: remetem ao que escapa aos nossos modelos, aos modelos das pessoas com as quais conhecemos/intervimos e pode levar à sua transformação (DELEUZE; GUATTARI, 1995).

Com essa aposta ético-política a nos fundamentar, embarcamos em uma produção nômade e ambulante que tinha como objetivo geral analisar a intersetorialidade a partir das relações estabelecidas no NIR-T que apresentamos anteriormente, enfatizando o modo de gestão do trabalho social entre as políticas setoriais, nas equipes e com as famílias com o intuito de favorecer a invenção de novas formas de expressão nesses grupos. Através dos encontros com esses grupos, das participações nas reuniões, das entrevistas individuais e coletivas, dos afetamentos, da análise da implicação, dentre outros, procuramos pôr em análise os efeitos das práticas no cotidiano institucional, desconstruindo modos sedimentados e reprodutivos e favorecendo a criação coletiva de outras atuações.

Utilizando a metodologia da pesquisa-intervenção, atuamos com duas linhas simultâneas para a produção de seus dados. O campo de análise se constituiu da leitura e discussão coletiva sobre as ideias de Gilles Deleuze, Félix Guattari, Michel Foucault e René Lourau, que sustentam a proposta de pesquisa-intervenção desse estudo, e autores nacionais que trabalham nessa vertente. Efetuamos, ainda, o estudo da intersetorialidade, focando na inclusão social, na violação de direitos e nas famílias usuárias. O campo de intervenção se constitui em um projeto de trabalho coletivo com a equipe dos profissionais que integram o 
NIR-T, versando sobre suas demandas, dificuldades e conflitos, incluindo reflexões sobre a dimensão político-institucional (organização do trabalho, relações entre os setores e equipes, relação com as famílias, poder frente aos procedimentos) e a dimensão socioassistencial.

Com a equipe analisamos a ignorância de cada setor no que se refere ao trabalho dos outros setores, o impacto dos casos graves na subjetividade dos técnicos, a descrença dos profissionais não só com a intersetorialidade, mas com suas próprias intervenções, o atravessamento do conselho tutelar, dentre outros. Dificuldades que coexistiam com a emergência desse núcleo como um espaço potente de construção de saídas coletivas, de discussão que os fortalece em uma partilha grupal de suas angústias, lugar que cria olhares distintos que desfocam a leitura do caso-problema, ampliando o conhecimento de todos ali, não só das questões discutidas, mas também das políticas e seus programas, dos territórios e suas singularidades.

No curso da pesquisa esperávamos ainda escutar e intervir com as famílias, certos de que estas não poderiam ser abordadas em sua totalidade ou universalidade, mas apostando nos encontros singulares para conhecê-las, desejando produzir conhecimento na relação, interferir em seus modos de vida. De fato, conhecer e intervir sustenta um processo que revela que não há neutralidade nessa produção e que o pesquisador implicado é também produzido pelas instituições que o atravessam, circula entre a academia e o que pretende estudar, engendrando e sendo engendrado por esses modelos e forças. Nessa perspectiva, a análise da implicação é inerente ao processo de produção de conhecimento. Essa análise consiste em questionar as instituições que nos atravessam no contato com o campo de intervenção, que sempre produz efeitos no pesquisador (ROMAGNOLI, 2014). Ou seja, o contato com as equipes e as famílias produziram inquietações e desassossegos, que remetiam a nossa história, ao nosso posicionamento ético-político, ao sistema de poder da academia, incluindo o próprio lugar de pesquisador, bem como aos compromissos com as agências de fomento.

Nessa produção de dados, tivemos certo sucesso com as equipes que foram muito colaborativas e participaram ativamente do processo de restituição. A restituição, a partir da Análise Institucional, diz do processo de análise de dados que é feito em conjunto com a população pesquisada e Monceau (2012, p. 30, tradução nossa) atesta que “[...] permite «testar» as interpretações, mas também, e pode ser sobretudo, de assegurar que o pacto de trabalho continue ativo entre todos os participantes" . Amador, Lazarotto e Santos (2015, p. 235) também baseadas nas ideias de René Lourau ressaltam que "A restituição e a participação, nesta perspectiva, não constituem uma concessão, mas uma estratégia analítica deste modo de pesquisar-intervir que torna necessário o movimento de composição de um coletivo pesquisador". A restituição feita em conjunto com a equipe do NIR-T permitiu que os profissionais expressassem o que esses percebiam da realidade que viviam nesse espaço e o que observavam em seu cotidiano, percepções usadas para a reflexão coletiva e apontadas acima. No que diz respeito aos efeitos da pesquisa nesse espaço, até onde podemos observar, houve conhecimento maior nesse dispositivo, rastreando as dificuldades e construindo algumas saídas. Porém, sabemos que podemos ter tido ainda resultados invisíveis que foram apropriados pelos profissionais e seguem atravessando sua forma de realizar seu trabalho. 
A ideia era fazer esse mesmo processo com as famílias, iniciando com as entrevistas individuais, e assim as mobilizando para as entrevistas coletivas, nas quais esperávamos haver um movimento grupal, uma vez que no coletivo há questionamentos, o que não ocorre no individual, pois as famílias têm medo de perder os benefícios das políticas públicas (ROMAGNOLI, 2018). Além disso, acreditávamos que o grupo seria um intercessor não somente para partilhar narrativas e experiências entre os familiares, mas sobretudo para convocar o coletivo, uma vez que a subjetividade se inventa nessa dimensão, através de agenciamentos, conexões com elementos do não-eu, entrelaçando imagens, afetos, devires, objetos, informações, histórias, emoções, dentre outros. Nesse processo, ocorrem experimentações que trazem as forças, o intensivo, presente nas situações (DELEUZE; GUATTARI, 1995). Era isso que pretendíamos buscar. Entretanto, essa etapa da pesquisa não se deu como esperava. Problematizamos esse dado na análise que se segue.

\section{Produção dos dados: (re)produzindo realidades}

No período destinado às famílias, apesar de inúmeras tentativas, tivemos muitos obstáculos para contatar essas pessoas. Inicialmente os familiares foram indicados pela equipe fixa do NIR Técnico, usando como critério o caso ter sido discutido nesse espaço intersetorial e os familiares terem condições de darem entrevistas, ponto sempre lembrado pelos técnicos que nos deram uma lista de nomes. Nos contatos iniciais que fizemos com os familiares, essa lista foi minguando: muitos tinham mudado de telefone, de casa, de regional. Marcamos mais uma reunião com os técnicos e refizemos a lista. Conseguimos fazer as três primeiras entrevistas individuais para depois fazer as entrevistas coletivas. Nosso plano era fazer 10, 12 entrevistas individuais para eles nos conhecerem, saberem da proposta e depois duas entrevistas coletivas com 5 a 6 familiares. Dessas três entrevistadas, uma não quis participar do encontro coletivo. Assim tínhamos somente duas pessoas dispostas a fazer a entrevista em grupo. Fizemos mais tentativas, agora diretamente com os técnicos que conhecíamos das equipes volantes. Tivemos vários impedimentos tanto para entrar em contato com eles como para convencê-los a nos ajudar: dificuldade de conseguir falar com os técnicos, indagações sobre o projeto, sobre o tipo de família que queríamos, sobre como seria a entrevista. Explicamos esses pontos. Mais indicações que não conseguimos entrar em contato... A equipe fixa entra novamente, tenta fazer a mediação. Mais nomes, mas dificuldades de contato. $\mathrm{O}$ tempo passa... A pesquisa, em seu cronograma, encaminha para o término. Tivemos que admitir a inviabilidade de conhecer/intervir com as famílias, a despeito de nosso desassossego acerca da falta de inclusão da visão dos usuários nos estudos sobre políticas públicas. Fala-se muito das equipes, dos profissionais, mas quem, de fato, usa a política e seus equipamentos raramente a avalia, a critica.

Não conseguimos produzir uma realidade na qual as famílias pudessem ter voz, se associar, fazer arranjos que dessem passagem à força do coletivo, da qual esperávamos ser intercessores. Foucault (2004) em seu texto "Genealogia e Poder", ao defender a genealogia, afastando-se da universalidade e da ideia de verdade sedimentada na modernidade, diz que essa tem duas características: o caráter local da crítica e a insurreição dos saberes dominados. 
Prudências, que, pensamos podem nos acompanhar nos nossos processos de pesquisa. Abordar o que estudamos, nossos parceiros do campo, nós mesmos, requer uma postura singular que se afasta da totalidade e das generalizações. Ao colocar nosso corpo na pesquisa, necessitamos prestar atenção nas instituições que falam através de nós, como nos lembra Lourau (1990), escutar as nossas vozes e a dos outros, que por muito tempo foram desqualificadas pelos nossos discursos científicos, dar ainda consistência às pequenas marcas que nascem entre nós e escapam das padronizações, dos traços de insuficiência, de impossibilidade, do risco sempre presente que esses grupos vivem. Entendemos que a opinião dos usuários nos permitiria ampliar a análise do exercício do cuidado na prática intersetorial, dos movimentos de acesso aos serviços, dos vínculos estabelecidos e da construção e efetividade dos encaminhamentos e outras questões que, certamente, emergiriam no encontro com as famílias. Além das experimentações-intervenções sustentadas pelo coletivo.

Sabemos que ao fazer pesquisa com os profissionais e as famílias, convocando composições outras entre nós, não temos domínio sobre o que planejamos. A vida tem seu próprio ritmo e desestabiliza a todos. "A construção do conhecimento se processa como ativadora e produtora de intervenção na vida e acontece nesta mistura, neste tingimento do pesquisador com o campo" (ABRAHÃO et al., 2013, p. 134). Assim, tingidos pelo campo, aceitamos sua autopoiese. A realidade tem autonomia e se faz por movimentos próprios parindo situações que são também dados que não estavam previstos no projeto de pesquisa e nem em seu cronograma. Acontecimentos analisadores em instituições que se fazem no jogo de forças instituídas que tendem à conservação do que existe e forças instituintes que buscam o frescor do novo. Forças coexistentes que geram crises, conflitos, contradições, irrompendo em práticas, situações denominadas de analisadores, frutos desse confronto entre o que se quer manter e o que se quer mudar. Os analisadores produzem desvios, questionamentos, desvelando essas forças ocultas (LOURAU, 2004).

Por essa perspectiva, entendemos a dificuldade de acesso aos usuários das políticas públicas como um analisador, que expressa alguns "não ditos" institucionais, algumas condições de produção dessa impossibilidade, buscando em nossa análise investigá-las. Esquadrinhar os "não-ditos" desnaturaliza algumas verdades e gera efeitos que podem vir a produzir agenciamentos, dando passagem à complexidade da produção de outros modos de existência. Essa desnaturalização abala nossas verdades e cria indagações que podem operar outras práticas de cuidado e de intervir com essas famílias.

Um primeiro atravessamento que é importante apontar, e que muitas vezes fica oculto nas pesquisas no campo das políticas públicas, refere-se à mudança na administração da prefeitura com a entrada de um novo prefeito, período no qual os que entram trazem questões instituintes e muitas vezes desconsideram o instituído, na ânsia de combater o governo precedente, ocasionando um período de reestruturação. Presas nas disputas macropolíticas, a equipe tem que se recompor, desativar programas antigos, inaugurar outros, readaptar-se aos novos gestores e nós, pesquisadores, somos obrigados a rever nossos prazos e restabelecer o vínculo com as equipes, pedir permissão novamente para o estudo. Vivenciamos essa reorganização exatamente no início da etapa destinada às entrevistas com as famílias. Nesse processo, ouço que a universidade tem pouca parceria com as instituições públicas, mas não é 
fácil lidar com elas. Macropolítica, maioria atravessando a micropolítica, minoria. Ou seja, percebemos a indissociabilidade dessas duas dimensões em que os trâmites administrativos e documentais que ordenam e classificam se aliam a questões menos visíveis que se fazem nas relações que são estabelecidas cotidianamente nos serviços. Ao estudar política em Deleuze e Guattari, Balconi (2018) mostra como esta é um imperativo prático se exercendo por agenciamentos complexos que se dão na micropolítica. $\mathrm{O}$ autor faz ainda a distinção entre as maiorias que buscam a padronização e que detêm o poder de normalização e as minorias, que fazem um apelo a formas diferentes de viver. Maioria e minoria que dizem respeito a processos da vida sociopolítica e institucional.

As famílias, como minorias, ficam assim mais apartadas do nosso estudo, enredadas nos trâmites da maioria que transita em nós e através de nós, funcionamentos institucionais que oprimem, que incapacitam na interface da produtividade exigida pelos programas de pósgraduação em nosso país e pelas tessituras com a nova gestão da prefeitura. Distanciam-se também pela sensação que as percorre de não ter o que falar. "Por que querem nos ouvir?" Sensação de indagação, agora nossa, quando as convidamos para dar suas impressões. No rastro da incompetência necessitamos de auxílio. Todos. Sentimo-nos todos incapazes: de fazer a pesquisa, de ser uma família que sabe criar seus filhos, de continuar a rotina de trabalho após tanta mudança na prefeitura, de ser um técnico que faz a diferença. Estamos separados da nossa potência. Da nossa parte, a porosidade do nosso corpo pesquisador sofre, cansado de conhecer/intervir somente com profissionais em nossas pesquisas: não conseguimos tensionar o instituído no que se refere aos usuários, embora o processo com a equipe tenha sido muito rico. Os vínculos com a nova equipe são ainda incipientes e delicados, em um momento no qual precisamos dela como mediadora no acesso às famílias.

Em uma conversa com uma das profissionais da equipe do NIR Técnico, questionamos porque não estávamos conseguindo a aproximação com as famílias. Começamos a nos indagar também, para além do atravessamento macropolítico, sobre o que se passava entre os técnicos e as famílias. Ela acha que eles não querem que os pesquisadores vejam sua atuação, acha que eles têm medo da crítica, por isso não facilitam os contatos. Além disso, precisam resguardar também o serviço no qual estão inseridos. Ao estudar os obstáculos para a materialização da intersetorialidade, Cavalcanti e Lucena (2016) fazem referência à sobrecarga de incumbências dos profissionais em seus setores, favorecendo a manutenção do conservadorismo das ações. Muitos profissionais, de fato, se sentem vulneráveis em suas atuações, como destaca Romagnoli (2015) ao estudar os efeitos do trabalho cotidiano com a vulnerabilidade. A autora pontua em seu estudo que a vulnerabilidade "[...] encontra reverberações em certas posturas das equipes, que muitas das vezes se sentem inseguras, desmotivadas e ressentidas em sua lida com a família [...]" (ROMAGNOLI, 2015, p. 456). Esse pode ter sido outro "não-dito" ativado pela busca dos usuários.

Embora essa tenha sido a leitura de uma das pesquisadas no que se refere ao receio acerca das entrevistas com as famílias, enxergamos nos técnicos, mais do que um esforço de se proteger, uma tentativa de preservar esses grupos através do poder do especialista, do seu lugar nos serviços. Ou seja, a proteção não era para eles mesmos, já que a maioria dos 
profissionais eram muito preparados e investidos em seu trabalho, mas sim para as famílias, para os usuários dos serviços. Enquanto esperávamos as indicações, ouvíamos as seguintes falas, que nos soavam como proteção a esses grupos: "Não está em um bom momento para conversar", "Agora eles estão em uma crise muito grande", "Vamos tentar outra família, porque esta que indicaram está muito frágil". Essas frases construíam barreiras contra o coletivo pesquisador, antecipando impedimentos para que a entrevista se realizasse, uma vez que se tratava de famílias muito vulneráveis, com casos complexos que percorrem toda a rede intersetorial. Mas por que essa necessidade de proteção?

Nesse momento em Belo Horizonte, os técnicos protegem os usuários com relação ao poder judiciário. Com uma interpretação equivocada do Estatuto da Criança e do Adolescente (ECA), as mães vulneráveis estão perdendo a guarda de seus bebês. Isso vem ocorrendo desde julho de 2016, por cumprimento da Portaria 3/2016. Nesses documentos, as maternidades de Belo Horizonte são obrigadas a acionar a Vara Cível da Infância e da Juventude, no prazo de 48 horas, contadas a partir do nascimento do bebê, quando houver evidências ou constatação de que a mãe é usuária de drogas e/ou tem trajetória de rua (TRIBUNAL DE JUSTIÇA DO ESTADO DE MINAS GERAIS - TJEMG, 2016). Essa resolução deflagra nos serviços uma necessidade de amparo a essas mães que querem permanecer com suas crianças e solicitam isso a partir do vínculo que têm com os técnicos, embora não necessariamente este seja o público do NIR-T. Mas a atmosfera se impregna de urgência de defesa. Esse "não-dito" respinga na pesquisa e eles precisam proteger as famílias também de nós. Proteção da própria universidade também como uma instituição de poder e de saber, que pode ameaçar do seu lugar de hierarquia do conhecimento. Ao sair de uma reunião de restituição na qual participa pela primeira vez uma gestora de uma das secretarias, ela diz, sem saber que estou escutando: "A gente tem que tomar cuidado com a universidade". Que perigo oferecemos?

Será que já que essas famílias são capazes de lidar com tanta privação, exclusão social, graves problemas cotidianos, são tão frágeis que não suportariam uma entrevista de pesquisa feita com cuidado e respeito aos preceitos éticos? Será que os técnicos não imaginam que a fragilidade vai além? A fragilidade/capacidade vem dos embates do cotidiano, não de falar sobre isso. Acredito que aqui temos o risco de a proteção virar tutela e se distanciar da autonomia que as políticas públicas propagam. Apesar de não termos conseguido interferir com e nas famílias, acompanhamos várias delas nas discussões do NIR Técnico, e nos chamou atenção a potência de padecer desses grupos. Para Deleuze (2002) em seu uso de Espinosa, as interações dos corpos, as relações firmadas produzem um campo de efeitos variáveis, de acordo com as composições feitas.

Quando os corpos se encontram, esse encontro pode ser compatível e compor um todo mais potente, constituindo uma nova relação, mas também pode ser incompatível e despotencializar, intoxicar. Assim, quando um corpo convém ao meu, sua potência se soma à minha, aumentando minha potência de agir, possibilitando que a vida se exerça em sua essência. No entanto, quando um corpo é inconveniente ao meu, exatamente porque sua potência se opõe à minha, o encontro com ele faz com que aflore a minha potência de padecer, de sofrer, que me separa da vida. 
Esse padecimento aparece nas discussões dos casos atravessados por problemáticas complexas, sustentadas por privações e misérias, no qual é preciso uma ação conjunta, intersetorial para tentar construir possibilidades para esses grupos que vivem as intervenções de uma forma passiva e que na maioria das vezes nem sabem que seu arranjo familiar está sendo discutido em um núcleo intersetorial. São modos de existir que habitam territórios sedentários e reprodutivos, precarizados em várias dimensões. Vida vivenciada como fatalidade e não como devir, presa em pontos inertes, fabricando famílias estigmatizadas, contornadas pela exclusão social, fracassadas em se inserir na sociedade. Por outro lado, Paulon e Romagnoli (2018) baseadas nas ideias de Nietzsche e Espinosa, defendem que há potência nos vulneráveis. Para além de leituras baseadas em um moralismo hierárquico, destacam que essa potência pode ser conquistada nos encontros entre técnicos e famílias, lógica relacional produtora de vida, não mais pontos endurecidos, mas linhas que ao serem percorridas criam, inventam.

As famílias também são redes vivas de produção, grupos nômades que podem habitar outros territórios. São essas famílias que nos interessam, que tem alegrias, comportam dores e dissabores, encontros com alteridades, diferenças que sustentam conflitos. Não as famílias docilizadas nas entrevistas individuais que só fazem enaltecer o trabalho dos serviços. "Assim, depois que conheci os serviços, mudou bastante, melhorou bastante", "Quando não tinha o serviço, era muito complicado", "Não sei o que seria de mim sem F. (técnica do CREAS)". Estas são algumas das frases que escutamos nas entrevistas individuais. Não que os serviços não sejam importantes na vida dessas pessoas, todavia as falas dizem de certa passividade e dependência dos serviços para continuarem sua vida, se afastando da autonomia preconizada pelas políticas públicas.

Ao mapear a avaliação de famílias em situação de vulnerabilidade social acerca do atendimento recebido no Centro de Referência em Assistência Social (CRAS), Andrade e Morais (2017) salientam como esses grupos ainda possuem uma mentalidade assistencialista, tendo dificuldade em reconhecer seus direitos sociais e identificando a importância do equipamento no território. Em sua avaliação as famílias percebem mais pontos positivos ligados ao atendimento, às atividades e aos benefícios do que pontos negativos associados à estrutura física, localização e rotatividade dos técnicos. Essa mesma postura foi percebida por Romagnoli (2018) nas entrevistas realizadas com famílias usuárias da política de assistência social, não aparecendo nenhum questionamento crítico por parte delas. Será que as famílias ainda acham que estão recebendo favores, atualizando a linha histórica da caridade e da benesse que durante muito tempo fez parte da assistência aos excluídos socialmente em nosso país? Será que não existe nenhuma tensão ou descompasso nos atendimentos? Por que quem usa não pode também evidenciar os conflitos presentes em serviços que não questionam as próprias condições de produção da vulnerabilidade?

Em nosso percurso de conhecer/intervir havia a inquietação sempre presente de tentar soltar as multiplicidades que estão endurecidas no vetor vulnerabilidade, presas nas fôrmas de desqualificação e culpabilização constante, efetuada inclusive pelas próprias famílias. Todas as pessoas e grupos possuem capacidades de invenção e de construção de saídas para o enfrentamento cotidiano das suas existências, na luta pela sobrevivência e é preciso que 
reconheçamos isso. Examinando a atuação da psicologia com famílias que não cumprem as condicionalidades do Programa Bolsa Família, Souza e Marin (2017) sustentam a importância do acolhimento para que as equipes possam ser intercessores em direção à autonomia. Sem dúvida, os técnicos acolhem, ajudam, mas em certas circunstâncias, geralmente sem se darem conta, tutelam, invadem, condenam, expropriam as famílias e eles mesmos da sua potência.

Um dos pontos que mais escutamos em nossa experiência com trabalhos com família refere-se à incapacidade das famílias de exercerem o cuidado e da dificuldade de criarem seus filhos. Não acreditamos nisso, embora seja uma região com altos índices de violência intrafamiliar. Nunca vimos uma família que não tratasse de seus membros, mesmo que não de forma dominante, que não tecesse relações de cuidado em sua singularidade, em seus modos peculiares de existir. A questão é que o cuidado muitas vezes não passa pelo carinho, pela higiene, pelos bons tratos, mas pela violência, pela agressão, pela imposição, dentre outros, geralmente perpetuando formas transgeracionais de se relacionar. E cabe aos técnicos acolher essas cristalizações de padrões que precarizam a vida, mas também e, sobretudo, que passam por capacidades de enfrentamento de situações, instáveis, árduas e pesadas. Ao problematizar o cuidado e saúde mental na sua relação com as famílias, Ferreira et al. (2016, p. 98) nos lembram: "A abertura para as apostas que os usuários fazem, cotidianamente, no seu caminhar pela vida nos convoca a problematizar a necessidade de se pensar o cuidado como a construção de espaços de escuta e reconhecimento do outro". Outro-alteridade, diferença bruta que nos desestabiliza com sua estranheza.

$\mathrm{Na}$ relação com essas famílias temos que sustentar a diferença como um modo de se abrir às divergências, aos potenciais da multiplicidade, da vida. Pensamos a diferença como um fluxo processual mais amplo que a pretensa totalização da unidade do ser consigo mesmo (DELEUZE; GUATTARI, 1995). Mundo das relações e das forças que escapam das fôrmas. Diferença como o que está além dos modelos transcendentes, das formas ideais de se relacionar e se compor como uma família, como profissional. É uma aposta política nas minorias, nos indivíduos e nas famílias que possuem singularidades que as instituições tentam capturar a todo custo. Essa singularidade pode persistir na fuga de qualquer forma de poder, de normatização da vida. Na verdade, há aqui uma aposta na capacidade dessas pessoas de (re)inventarem.

\section{Considerações finais}

Esse texto apresenta mais indagações que respostas, desassossegos que se manifestaram no processo da pesquisa-intervenção que levamos a cabo, problematizando situações que surgiram no encontro com o campo de pesquisa, no que se refere à participação das famílias. Dessa maneira, trata da imprevisibilidade e dos desafios que afloram quando estamos produzindo conhecimento com e não sobre as populações que pesquisamos. Certamente o exercício investigativo lida com incertezas e inesperados que são, de fato, os fios da produção de conhecimento com os quais também tramamos nossas pesquisas. No 
coletivo de atores que nos desestabiliza e nos faz problematizar, vivemos os impasses de como conhecer, desestabilizando nossas lógicas de poder.

As políticas públicas são essenciais para a garantia de direitos, para o resgate da cidadania e da autonomia de seus usuários. No entanto, ainda pudemos notar em nosso estudo uma dificuldade de apropriação dessas políticas pelos atores que as vivem cotidianamente, seja como executores, seja como público alvo. Nesse cenário, ações coletivas podem traçar deslocamentos a esta não apreensão, muitas delas sustentadas pelas práticas intersetoriais. Ações coletivas entre equipes de diferentes setores, entre os profissionais de uma mesma equipe e, principalmente, com a família que demanda a intersetorialidade. Investigar essa prática intersetorial é também e, sobretudo, escutar os usuários que são ativos no processo de construção de suas vidas e dos seus enfrentamentos. Para não corrermos o risco, sempre presente, de estabelecermos relações assimétricas com esses grupos, nas quais queremos que o outro seja cuidado dentro do que entendemos e nosso olhar para as famílias seja previsível. As famílias produzem dinâmicas, modos de existência certamente cheios de tensões e problemas, mas também são redes vivas de produção de vida e não podemos nos afastar das suas multiplicidades.

\section{Referências}

ABRAHÃO, Ana Lúcia et al. O pesquisador in-mundo e o processo de produção de outras formas de investigação em saúde. Lugar Comum, n. 39, p. 133-144, 2013.

AMADOR, Fernanda Spanier; LAZZAROTTO, Gislei Domingas Romanzini; SANTOS, Nair Iracema Silveira dos. Pesquisar-agir, pesquisar-intervir, pesquisar-interferir. Revista Polis e Psique, Porto Alegre, v. 5, n. 2, p. 228-248, 2015. Disponível em: http://seer.ufrgs.br/index.php/PolisePsique/article/view/58180/pdf_26. Acesso em: 22 mar. 2018.

ANDRADE, Anne Graça de Sousa; MORAIS, Normanda Araújo de. Avaliação do atendimento recebido no CRAS por famílias usuárias. Psicologia: Ciência e Profissão, v. 37, n. 2, p. 378-392, 2017.

BALCONI, Lucas Ruiz. Direito e política em Deleuze. 1. ed. São Paulo: Idéias e Letras, 2018.

CAVALCANTI, Patrícia Barreto; LUCENA, Carla Mousinho Ferreira. O uso da promoção da saúde e a intersetorialidade: tentativas históricas de integrar as políticas de saúde e educação. Polêmica, Rio de Janeiro, v. 16, n. 1, p. 24-41, jan./mar. 2016.

DELEUZE, Gilles. Espinosa: filosofia prática. São Paulo: Escuta, 2002.

DELEUZE, Gilles; GUATTARI, Félix. Introdução: rizoma. In: DELEUZE, Gilles; GUATTARI, Félix (Org.). Mil Platôs: capitalismo e esquizofrenia. Tradução Aurélio Guerra Neto e Celia Pinto Costa. Rio de Janeiro: Editora 34, v. 1, 1995. p. 11-37. 
DELEUZE, Gilles; GUATTARI, Felix. Tratado de Nomadologia: A Máquina de Guerra. In: DELEUZE, Gilles; GUATTARI, Félix (Org.). Mil Platôs: capitalismo e esquizofrenia. Tradução Peter Pál Pelbart e Janice Caiafa. Rio de Janeiro: Editora 34, v. 5, 1997. p. 07-95.

FERREIRA, Thayane Pereira da Silva et al. O reconhecimento do saber do outro como válido: as apostas que os usuários fazem sobre sua vida $\mathrm{x}$ a decisão dos trabalhadores de saúde sobre a vida do outro. In: MERHY, Emerson Elias et al. (Org.). Avaliação compartilhada do cuidado em saúde: surpreendendo o instituído nas redes. Rio de Janeiro: Hexis, 2016. p. 96-99.

FOUCAULT, Michel. Microfísica do poder. 20 ed. Rio de Janeiro: Graal, 2004.

LOURAU, René. Implication et surimplication. La revue du Mauss. Paris, n. 10, p. 110-119, 1990.

LOURAU, René. Objeto e método da Análise Institucional. In: ALTOÉ, Sônia (Org.). René Lourau: analista institucional em tempo integral. São Paulo: Hucitec, 2004. p. 66-86.

MONCEAU, Gilles. Tecchiques socio-cliniques pour l'analyse institutionnelle des pratiques. In: MONCEAU, Gilles (Org.) L'analyse institutionnelle des pratiques: une socio-clinique des tourments institutionnels. Paris: L'Harmattan, 2012. p. 15-35.

MONNERAT, Giselle Lavinas; SOUZA, Rosimary Gonçalves de. Da seguridade social à intersetorialidade: reflexões sobre a integração das políticas sociais no Brasil. Revista Katálysis, Florianópolis, v. 14, n. 1, jun. 2011.

OLIVEIRA, Clever Manolo Coimbra; HECKERT, Ana Lúcia Coelho. Os Centros de Referência de Assistência Social e as artes de governar. Fractal: Revista de Psicologia, Niterói, v. 25, n. 1, p. 145-160, abr. 2013.

PAULON, Simone Mainieri; ROMAGNOLI, Roberta Carvalho. Quando a Vulnerabilidade se faz Potência: notas acerca de um conceito polissêmico nas políticas públicas. Interação em Psicologia, v. 22, n. 3, p. 178-187, dez. 2018.

PASSOS, Eduardo; BARROS, Regina Benevides de. A cartografia como método de pesquisa-intervenção. In: PASSOS, Eduardo; KASTRUP, Virgínia; ESCÓSSIA, Liliana da Pistas do método da cartografia: pesquisa-intervenção e produção de subjetividade. Porto Alegre: Sulina, 2015. p. 17-31.

ROMAGNOLI, Roberta Carvalho. As relações entre as famílias e a equipe do CRAS. Fractal: Revista de Psicologia. Niterói, v. 30, n. 2, p. 214-222, maio/ago. 2018.

ROMAGNOLI, Roberta Carvalho. Problematizando as noções de vulnerabilidade e risco social no cotidiano do SUAS. Psicologia em Estudo. Maringá, v. 20, n. 3, p. 449-459, jul./set. 2015.

ROMAGNOLI, Roberta Carvalho. O conceito de implicação e a pesquisa-intervenção institucionalista. Psicologia e Sociedade. Belo Horizonte, v. 26, n. 1, p. 44-52, abr. 2014. 
SANTOS, Keli Lopes; HECKERT, Ana Lucia Coelho; CARVALHO, Silvia Vasconcelos. Família e mulher como instrumentos de governo na assistência social. Psicologia e

Sociedade, Belo Horizonte, v. 29, e158080, p. 1-10, 2017.

SOUZA, Xismara Rodrigues de; MARIN, Angela Helena. Intervenção com famílias em descumprimentos das condicionalidades do Programa Bolsa Família. Saúde e sociedade, São Paulo, v. 26, n. 2, p. 596-605, jun. 2017.

TRIBUNAL DE JUSTIÇA DO ESTADO DE MINAS GERAIS - TJEMG. Portaria 3/2016. Dispõe sobre o procedimento para encaminhamentos de crianças recém-nascidas e dos genitores ao Juízo da Infância e da Juventude, assim como oitiva desses, nos casos de grave suspeita de situação de risco, e sobre o procedimento de medidas de proteção. Diário do Judiciário Eletrônico, Belo Horizonte, MG, 22 de julho de 2016.

WARSCHAUER, Marcos; CARVALHO, Yara Maria de. O conceito de "Intersetorialidade": contribuições ao debate a partir do Programa Lazer e Saúde da Prefeitura de Santo André/SP. Saúde e sociedade, São Paulo, v. 23, n. 1, p. 191-203, mar. 2014.

\section{Notas}

\footnotetext{
${ }^{i}$ No original: «(...) permet de «tester» des interprétations mais aussi, et peut-être surtout, de s'assurer que le pacte de travail reste actif entre tous les participants.»
}

\section{Agradecimentos:}

CNPq e FAPEMIG. 